\title{
Review of Cohort Studies for Mood Disorders
}

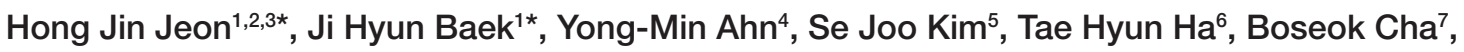 \\ Eunsoo Moon ${ }^{8}$, Hee-Ju Kang ${ }^{9}$, Vin Ryu ${ }^{10}$, Chul-Hyun Cho' ${ }^{11}$, Jung-Yoon Heo', Kiwon Kim', \\ Heon-Jeong Lee ${ }^{11} \bowtie$, and Mood Disorders Cohort Research Consortium (MDCRC) Group
}

${ }^{1}$ Department of Psychiatry, Depression Center, Samsung Medical Center, Sungkyunkwan University School of Medicine, Seoul, Republic of Korea ${ }^{2}$ Department of Health Sciences \& Technology, Department of Clinical Research Design and Evaluation, and Department of Medical Device Management and Research, Samsung Advanced Institute for Health Sciences \& Technology (SAIHST), Seoul, Republic of Korea ${ }^{3}$ Depression Clinical and Research Program, Massachusetts General Hospital, Harvard Medical School, Boston, MA, USA ${ }^{4}$ Department of Psychiatry, Seoul National University College of Medicine, Seoul, Republic of Korea

${ }^{5}$ Department of Psychiatry and Institute of Behavioral Science in Medicine, Yonsei University College of Medicine, Seoul, Republic of Korea ${ }^{6}$ Department of Psychiatry, Seoul National University Bundang Hospital, College of Medicine, Seoul National University, Seoul, Republic of Korea ${ }^{7}$ Department of Psychiatry, Gyeongsang National University College of Medicine, Jinju, Republic of Korea ${ }^{8}$ Department of Psychiatry, Pusan National University School of Medicine, Busan, Republic of Korea

${ }^{9}$ Department of Psychiatry, Chonnam National University College of Medicine, Gwangju, Republic of Korea

${ }^{10}$ Department of Psychiatry, Seoul National Hospital, Seoul, Republic of Korea

${ }^{11}$ Department of Psychiatry, Korea University College of Medicine, Seoul, Republic of Korea

This paper aimed to review currently available cohort studies of subjects with mood disorders such as major depressive disorder (MDD) and bipolar disorder (BD). Using the PubMed and KoreaMed databases, we reviewed eight major cohort studies. Most studies recruited participants with MDD and BD separately, so direct comparison of factors associated with diagnostic changes was difficult. Regular and frequent follow-up evaluations utilizing objective mood ratings and standardized evaluation methods in a naturalistic fashion are necessary to determine detailed clinical courses of mood disorders. Further, biological samples should also be collected to incorporate clinical findings in the development of new diagnostic and therapeutic approaches. An innovative cohort study that can serve as a platform for translational research for treatment and prevention of mood disorders is critical in determining clinical, psychosocial, neurobiological and genetic factors associated with long-term courses and consequences of mood disorders in Korean patients.

Psychiatry Investig 2016;13(3):265-276

Key Words Cohort study, Mood disorder, Bipolar disorder, Major depressive disorder, Review.

\section{INTRODUCTION}

Mood disorders are relatively common mental illnesses that are notorious for high disease burden and chronicity., ${ }^{1,2}$ Disease course and treatment responses in mood disorders varies from person to person because they are associated with an interplay of socio-cultural and genetic-biological factors. Major mood disorders, including major depressive disorder (MDD) and bipolar disorder (BD), have profound social impacts due

Received: October 12, 2015 Revised: December 23, 2015

Accepted: December 23, 2015 Available online: March 23, 2016

$\bowtie$ Correspondence: Heon-Jeong Lee, MD, PhD

Department of Psychiatry, Korea University College of Medicine, 73 Inchon-ro, Seongbuk-gu, Seoul 02841, Republic of Korea

Tel: +82-2-920-6721, Fax: +82-2-929-7679, E-mail: leehjeong@korea.ac.kr

*These authors contributed equally to this work.

(c) This is an Open Access article distributed under the terms of the Creative Commons Attribution Non-Commercial License (http://creativecommons.org/licenses/by$\mathrm{nc} / 3.0$ ) which permits unrestricted non-commercial use, distribution, and reproduction in any medium, provided the original work is properly cited. to increased suicide risk and decreased functional levels and quality of life. ${ }^{3-6}$ Despite recent advancements in the diagnosis and treatment of mood disorders, it is still difficult to predict treatment response and disease courses. Delayed diagnosis and diagnostic conversion from MDD to $\mathrm{BD}$ are making clinical decision making more difficult. Furthermore, long-term effects of currently available treatments on mood disorders are unclear. Novel approaches for early detection of and intervention for mood disorders are necessary.

A better understanding of long-term clinical courses is crucial for finding clinically meaningful biomarkers for early diagnosis and intervention. Cohort studies can provide valuable information on the clinical courses of mood disorders and the effects of treatments on the course of mood disorders.? Various prior cohort studies of mood disorders are available, yet each study has limitations in explaining the complexity of clinical presentation of mood disorders. 
In this paper, as part of a preliminary investigation for a prospective cohort study of Korean patients with mood disorders, we reviewed all currently available findings from major cohort studies of patients with mood disorders, including MDD and BD Through this review process, we propose an efficient study design that is suitable for capturing the real-world clinical setting in Korea.

\section{METHODS}

We searched the currently available literature based on cohort studies of mood disorders using databases such as PubMed and KoreaMed. The search for relevant publications was carried out using the terms 'cohort study', 'design', 'methodology', 'mood disorder', 'depression', and 'bipolar disorder'. We had screened all abstracts of publications through the two databases. As this review focused on adult populations, we excluded literature involving children, adolescents and the elderly. We included cohort studies that followed clinical courses of mood disorders using relatively standardized methodology. We excluded any literature that was not directly associated with mood disorders or conducted in a single center. After a careful review process, we selected eight major cohort studies using standardized evaluation methods for this review. We explored the design and methodology of each study and summarized the studies' major findings and limitations.

\section{RESULTS (Table 1)}

\section{Naturalistic cohort study with community population}

\section{The Lundby study}

The Lundby study is a longitudinal cohort study of a geographically defined population consisting of 3563 subjects. This study was designed to investigate the distribution of personality traits and mental disorders. ${ }^{8}$ The first field investigation started in 1947, and another investigation began in 1957 to include additional participants who had moved into the geographic area. Ninety-nine percent of the subjects were interviewed by psychiatrists. The interviews, most of which were conducted face-to-face, were carried out in 1947, 1957, 1972 and 1997.

At each time point, subjects participated in a semi-structured interview consisting of questions about their sociodemographic background, somatic health, mental health, medical service use, and life events that had taken place during the period since the last interview. Along with to the face-to-face interview, investigators contacted key informants to obtain additional reliable information. Also, investigators had access to case notes and several registers, including the Patient Register, which contained information about all inpatient care in Sweden from 1972 to 1997. ${ }^{9}$ The final evaluations of the clinical diagnoses took place after collecting all available information and determining a best-estimate diagnosis.

Since the DSM system ${ }^{10}$ was not available at the time of the study, the main categories of the Lundby diagnostic system are: depression, anxiety disorders, tiredness, mixed neurosis, schizophrenia, other psychoses, organic syndrome, and dementia. This is a hierarchical diagnostic system; that is, only one diagnosis per episode was registered. The Lundby diagnosis of depression remained unchanged during the study period.

After excluding subjects with preexisting alcohol problems or depression, 344 subjects (116 males, 228 females) who experienced their first depressive episode between 1947 and 1997 were examined to explore long-term courses of depression. ${ }^{11}$ The median age of the first onset of depression was around 35 years for individuals followed for $30-49$ years. The recurrence rate was approximately $40 \%$ and ranged from $17 \%$ to $76 \%$ depending on the follow-up duration. A transition to diagnoses other than depression occurred for $21 \%$ of the total sample, with alcohol disorders in $7 \%$ and $\mathrm{BD}$ in $2 \%$. Only $5 \%$ committed suicide; here, male gender and severity of depression were significant risk factors.

\section{Limitation}

The main limitation of the Lundby study is the diagnostic system applied. Taking into consideration the high comorbidity of mood disorders, a hierarchical system is not sufficient to evaluate the complex nature of mood disorders. Also, the interval of follow-up evaluations was too sparse to explore clinical courses in detail. ${ }^{12}$

\section{The Zurich study}

The Zurich study ${ }^{13}$ selected 4547 participants, 2201 males and 2346 females aged 19 and 20, respectively, from the canton of Zurich in Switzerland in 1978. At baseline, they were screened with the Symptom Checklist 90-R (SCL-90-R) ${ }^{14}$ in order to select for participants with high global severity indices (GSI) who would be more likely to develop psychiatric syndromes. A stratified random sample of 591 individuals (292 males, 299 females), two-thirds of whom were high scorers (defined as those scoring above the 85th percentile on the GSI), was selected for a follow-up interview. Following the initial screening in 1978, six subsequent interview waves were conducted across 20 years.

Psychiatric residents and clinical psychologists carried out the follow-up interviews using the Structured Psychopathological Interview and Rating of the Social Consequences for Epidemiology (SPIKE). The SPIKE evaluates a broad range of psychiatric and somatic syndromes and symptoms through 


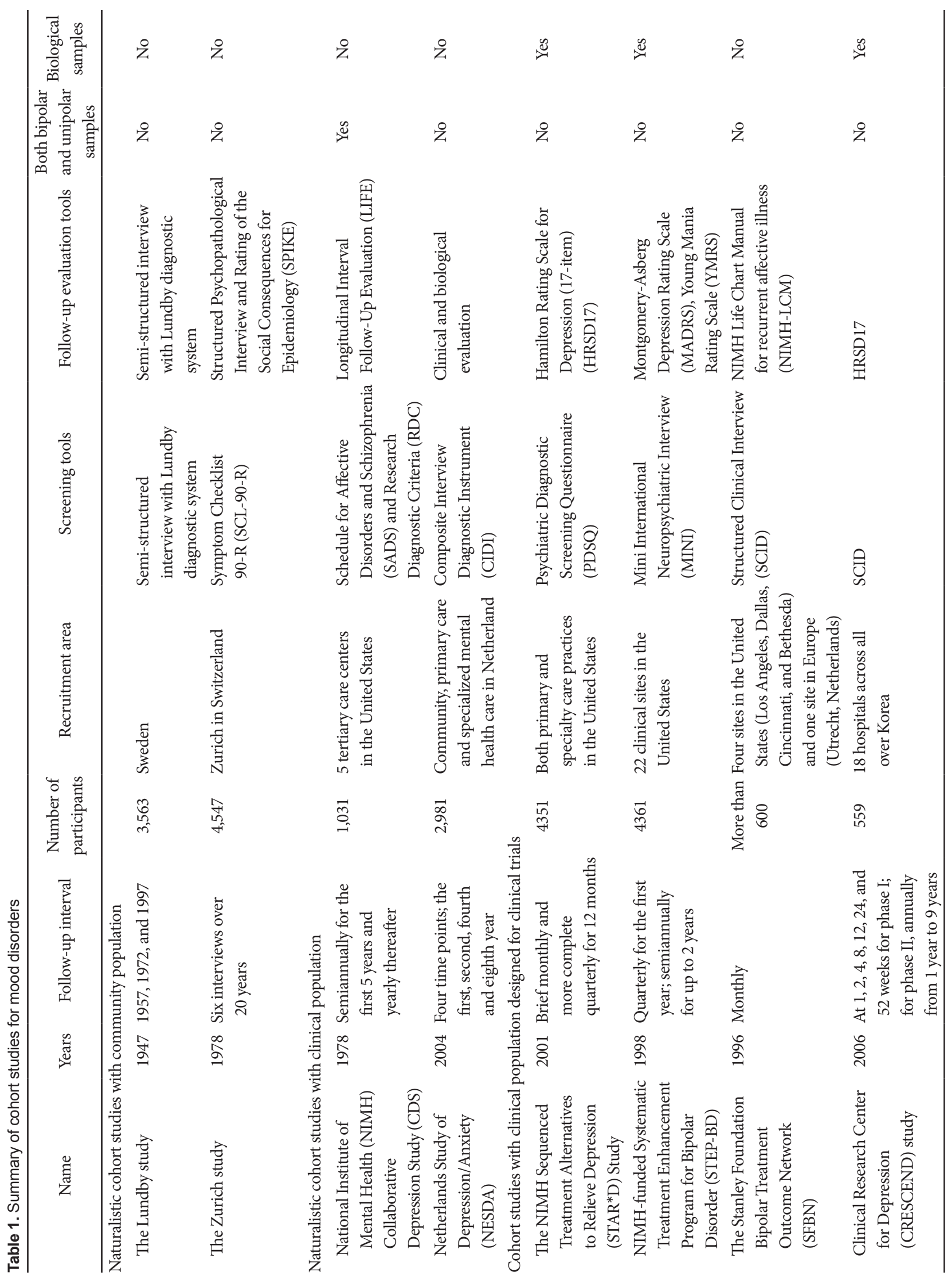


questions regarding duration, frequency, treatment and subjective impairment and distress. All psychiatric diagnoses were made based on DSM-III-R and DSM-IV criteria. ${ }^{10}$

\section{Major findings}

The Zurich cohort study provided a valuable opportunity to examine the chronicity and diagnostic stability of mood disorders. ${ }^{15}$ The presence of MDD predicted heart complications and an increase in long-term body weight variability. ${ }^{16}$ Comorbid anxiety and depression tended to be more stable than either syndrome alone, suggesting the importance of comorbidity in clinical courses. Melancholic depression showed a more severe clinical course than atypical depression. Chronic depression, during which a major depressive episode lasts longer than 2 years, was associated with an earlier onset, worse clinical symptoms, more frequent psychiatric comorbidity, and poorer functional level and physical condition relative to episodic depression. ${ }^{17}$ Combined agitated and retarded major depressive states were associated with a transition to $\mathrm{BD}$, while pure agitated depression was less frequently associated with $\mathrm{BD} .{ }^{18}$ Relative to MDD, BD was more closely associated with the development of alcohol and benzodiazepine use disorders. ${ }^{19}$

\section{Limitation}

The Zurich cohort study explored clinical courses of mood disorders among patients ages 20 to 40, which limits the generalizability of the findings to people over 40 years old. The relatively infrequent evaluations and lack of biological measures limit the applicability of study findings.

\section{Naturalistic cohort study with clinical population}

\section{National Institute of Mental Health Collaborative Depression Study}

The NIMH CDS is the lengthiest longitudinal study of clinical courses of mood disorders. Inpatients and outpatients who were experiencing an active affective episode were recruited from 5 tertiary care centers in the United States between 1978 and $1981 .^{20}$ A total of 1,031 subjects with MDD, manic disorder, schizoaffective disorder and intermittent depressive disorder were enrolled, and long term follow-up evaluations were conducted for 31 years.

At the initial intake, a semi-structured interview using the Schedule for Affective Disorders and Schizophrenia (SADS) ${ }^{21}$ and the Research Diagnostic Criteria (RDC) ${ }^{22}$ was conducted to confirm subjects' diagnoses. Functional levels, a personality battery, and family history were also collected. The followup evaluations were based on the Longitudinal Interval Follow-up Evaluation (LIFE) ratings. ${ }^{23}$ The LIFE ratings determine the symptom severity of each affective disorder on a 6-point Likert scale based on whether symptoms meet RDC's definite criteria (1: usual self; 2: residual; 3: partial remission; 4: marked; 5: definite criteria; and 6: definite criteria, severe). The Longitudinal Interval Follow-up Evaluation Range of Impaired Functioning Tool (LIFE-RIFT) ${ }^{24}$ evaluates subjects' functional levels in the domains of work, interpersonal relations, recreation, and global satisfaction on a 5-point Likert scale ( $1=$ no impairment; $5=$ severe impairment). Trained raters interviewed participants every 6 months for the first 5 years and yearly thereafter, using variations of the LIFE and LIFE-LIFT ratings.

\section{Major finding}

A major strength of the CDS is that patients having diverse affective spectrum diseases, including MDD, bipolar I disorder, and bipolar II disorder, were recruited together and evaluated using uniform evaluation methods. As a result, we were able to see differences between the courses of these affective spectrum diseases. Both MDD and BD were chronic and recurrent disorders that caused significant psychosocial disability. ${ }^{25-27}$ Most subjects experienced subthreshold residual symptoms even when they were not in an acute episode, which had negative effects on their prognosis. ${ }^{28}$ Comorbid anxiety, substance use disorder, double depression and longer episodes predicted negative treatment responses. ${ }^{29}$ In $\mathrm{BD}$, depressive episodes and symptoms dominated overall clinical courses and were more disabling than (hypo)manic episodes and symptoms. ${ }^{27,30-32}$ Strikingly, one-fourth of subjects with MDD eventually became diagnosed with $\mathrm{BD} .{ }^{33}$ The main risk factor for the transition was subthreshold manic/hypomanic symptoms.

The CDS established the foundation for biological and clinical research of mood disorders through a comprehensive longterm evaluation using phenomenological, diagnostic, and genetic approaches. Major findings from the CDS have contributed to the study design of treatment strategies for mood disorders, such as the Sequenced Treatment Alternatives to Relieve Depression $\left(\mathrm{STAR}^{*} \mathrm{D}\right)^{34}$ and the Systematic Treatment Enhancement Program for Bipolar Disorder (STEP-BD). ${ }^{35}$

\section{Limitations}

Only Caucasians were included in the genetic studies, which limits the generalizability of the study findings. In addition, an early-age onset population was not included, so the lifetime course of mood disorder from the early period of mood disorders was not explored. Although the study was done prospectively, each follow-up evaluation using the LIFE and LIFE-RIFT was a retrospective evaluation that took place every 6 months or 1 year. Consequently, the follow-up evaluations may have been prone to recall biases. Although LIFE had 
a high intraclass correlation coefficient, more detailed and objective assessments for mood symptoms and suicidality at each follow-up period were not included in the study. This could have compensated for this major limitation of the LIFE and LIFE-RIFT evaluation.

\section{Netherlands Study of Depression/Anxiety}

The NESDA is a multi-site naturalistic cohort study describing the long-term course and consequences of depressive and anxiety disorders. ${ }^{36}$ The NESDA followed 2981 participants ages 18 to 65 for eight years. In order to increase the generalizability of the study, subjects were recruited from various health care settings (community, primary care, and specialized mental health care) and at various stages of the disorder's developmental history (normal, high familial risk, subthreshold disorders, first and recurrent episodes). Among all participants, 1701 subjects had depression (with or without a comorbid anxiety disorder), had a lifetime diagnosis, or were at risk due to a family history of subthreshold symptoms.

The Composite Interview Diagnostic Instrument (CIDI)Lifetime Version ${ }^{37}$ was used to confirm the diagnoses based on DSM-IV criteria. ${ }^{10}$ Information from a detailed clinical interview, self-report questionnaire, medical examination, brain functional magnetic resonance imaging (fMRI), cognitive computer task and blood and saliva samples were collected at baseline.

The follow-up evaluations were conducted at four time points: one year, two years, four years, and eight years after the initial assessments. The one-year follow-up assessment consists of questionnaires to determine demographic changes, recent life events and the course and consequences of anxiety and depression symptoms. The two-year follow-up assessment includes a face-to-face clinic visit in addition to the questionnaires given at the one-year follow-up assessment. During the clinic visit, participants complete a clinical interview, computerized cognitive tasks, and an additional questionnaire regarding seasonality.

\section{Major findings}

So far, findings from the two-year follow-up assessments are available. The comorbid depression-anxiety group showed a more chronic course than the pure depression group. Predictors of poor clinical course were severity and duration of index episode, comorbidity, earlier onset age, and older age. The NESDA incorporates a comprehensive clinical and biological evaluation that offers a unique opportunity to explore the long-term course of depression. Contrary to other cohort studies of populations with mood disorders, the NESDA increases the generalizability of study findings by including a variety of clinical populations. In addition, the study utilizes various biological measures, such as cognitive and neuroimaging evaluations, which can be valuable biomarkers in determining clinical outcomes of mood disorders.

\section{Limitations}

The main limitation of the NESDA study is the lack of frequent evaluations during the observational period. Since follow-up assessments are conducted at one-year, two-year, fouryear, and eight-year time points, we cannot evaluate detailed mood fluctuations during each time interval. Recall biases are also inevitable in this study design.

\section{Cohort studies with clinical population designed for clinical trials}

\section{The NIMH Sequenced Treatment Alternatives to Relieve Depression Study \\ The NIMH-funded STAR*D study is a multisite, prospec-} tive, randomized, multistep clinical trial of patients with nonpsychotic MDD. ${ }^{34}$ The STAR*D aimed to determine effectiveness of different treatments, including non-pharmacological treatments, for MDD that did not respond to the initial treatment. The STAR*D also aimed to describe the incidence, nature, and course of symptoms and functioning for those entering the 12-month naturalistic follow-up. ${ }^{38}$

At baseline, the Psychiatric Diagnostic Screening Questionnaire (PDSQ) ${ }^{39}$ was used to confirm DSM-IV based psychiatric diagnoses. The 17-item Hamilton Rating Scale for Depression (HRSD17), ${ }^{40}$ the 16-item Quick Inventory of Depressive Symptomatology-Clinician Rating (QIDS-CR) and the Quick Inventory of Depressive Symptomatology-Self-Report (QIDS$\mathrm{SR})^{41}$ were used to determine the severity of depression symptoms. Clinical Global Impression-Improvement, ${ }^{42}$ QIDS-CR, QIDS-SR and questionnaires regarding side effects and functional levels were used for follow-up evaluation. The primary outcome measure was the $\mathrm{HRSD}_{17}$, which was administered at the end of each treatment level by independent phone interviewers.

The STAR*D used broad inclusion and minimal exclusion criteria; subjects between ages 18 and 75 who met the criteria for single or recurrent non-psychotic MDD with a HRSD score less than or equal to 14 were included in the study. Participants with an adequate symptomatic response entered the 12-month naturalistic follow-up phase, which involved brief monthly as well as more thorough quarterly assessments. The study also collected subjects' blood samples for genetic analysis.

Major findings
The STAR*D study provided crucial information on decid- 
ing treatment sequence through detailed treatment responses and clinical presentations of individuals with non-psychotic MDD. ${ }^{43}$ It also revealed clinical factors associated with treatment responses and prognosis. A total of 4351 subjects from both primary and specialty care practices were enrolled in the study. Remission rates for treatment levels 1 through 4 were $36.8 \%, 30.6 \%, 13.7 \%$ and $13.0 \%$, respectively. ${ }^{44}$ There was no difference in effectiveness between any treatments at any treatment level. Patients with longer index episodes, more concurrent psychiatric or general medical disorders, and/or lower measures of baseline function were less likely to achieve remission. There were no major differences in outcomes between patients treated in primary versus specialist care, ${ }^{45}$ nor were there significant differences in depression rating scores obtained through clinician ratings versus self-report. This study also evaluated various clinical trials, including non-pharmacological treatment for treatment-resistant depression, none of which showed superiority over other treatment modalities. ${ }^{46-48}$

In addition to clinical trials, the STAR*D also explored various clinical characteristics that could affect treatment responses and the prognosis of MDD. As reflected in the DSM-5 diagnostic system, the study confirmed the importance of anxiety in clinical courses of MDD. ${ }^{49}$ About $20 \%$ of participants with MDD had chronic depression, ${ }^{50}$ which exhibited poorer prognosis. Recent manic-like symptoms and family histories of $\mathrm{BD}$ were associated with conversion to $\mathrm{BD}$, while irritability and antidepressant resistance were not associated with the conversion. ${ }^{51,52}$ General medical comorbid conditions were not uncommon in MDD, and they affected the severity of the depression. ${ }^{53,54}$ Age of onset ${ }^{55}$ and episode duration ${ }^{56}$ did not change the likelihood of remission. Using blood samples collected from subjects, genetic association studies integrating detailed clinical observations and genetic variances were conducted. ${ }^{57-64}$

\section{Limitations}

Because the STAR*D study aimed to conduct clinical trials from the outset, there may have been a bias in the recruitment processes. Detailed clinical observation is one of the major strengths of the STAR*D study, but it also can limit initial study participation. In addition, populations with psychotic depression, not uncommon in clinical practice, were not included in the study.

\section{The NIMH-funded Systematic Treatment Enhancement Program for Bipolar Disorder}

The STEP-BD is a multisite and prospective treatment study for $\mathrm{BD} .{ }^{35}$ Similar to the STAR*D project for non-psychotic $\mathrm{MDD}$, the STEP-BD projects aimed to determine the effectiveness of various treatment modalities for $\mathrm{BD}$ in both the acute and maintenance phases. Like the STAR*D project, the STEP$\mathrm{BD}$ also aimed to observe a naturalistic clinical course for 12 months. It incorporated both randomized controlled clinical studies and uncontrolled, evidence-based clinical care. ${ }^{65}$

Considering the complexity of the clinical presentation of $\mathrm{BD}$, the STEP-BD was designed to include the full spectrum of bipolar patients seeking clinical care. All patients with bipolar subtypes, including bipolar I, II, bipolar not otherwise specified (NOS), and cyclothymia, who were in any phase of the illness for longer than 15 years were able to take part in the study. Regardless of whether patients participated in the naturalistic study or the randomized trials, they received identical ongoing assessments of treatment and outcome information. Blood samples were also collected for the genetic analyses.

Diagnoses were confirmed through the administration of the Mini International Neuropsychiatric Interview (MINI) ${ }^{66}$ and a standardized affective disorder evaluation $(\mathrm{ADE})^{67}$ by a clinical specialist (a psychologist or social worker) and the treating psychiatrist, respectively. For symptom evaluation, various questionnaires were used to consider the complex symptom presentation of $\mathrm{BD}$; interviewers administered the Montgomery-Asberg Depression Rating Scale (MADRS), ${ }^{68}$ Young Mania Rating Scale (YMRS), ${ }^{69}$ Liebowitz Social Phobia Scale, ${ }^{70}$ Panic Disorder Severity Scale, ${ }^{71}$ and Yale-Brown Obsessive Compulsive Scale. ${ }^{72}$ Subjects also completed various self-report questionnaires, including the Beck Depression Inventory Version II (BDI-II), ${ }^{73}$ NEO Five-Factor Inventory, ${ }^{74}$ ADHD Symptom Checklist, Eating Disorder Inventory, Fear Questionnaire, Beck Anxiety Inventory, ${ }^{75}$ Beck Hopelessness Scale, and SF-36 Health Survey. ${ }^{76}$ These questionnaires and rating scales were utilized for both the baseline and followup assessments. The YMRS and the MADRS were the primary assessments of mood symptoms. Independent study assessments were scheduled at baseline and quarterly for the first year and then semiannually for up to 2 years.

\section{Major findings}

A total of 4,361 subjects with bipolar spectrum disorder across 22 clinical sites in the United States were enrolled in the study. The STEP-BD study explored the efficacy of antidepressant use for $\mathrm{BD}$, which has been controversial. In general, antidepressant use had neither benefit nor risk relative to the use of mood stabilizer alone. ${ }^{77}$ In a randomized study, patients who successfully recovered with both antidepressants and mood stabilizers were assigned to either the antidepressant plus mood stabilizer or the mood stabilizer alone treatment groups; no significant difference in the recurrence rate or the duration of remission was observed between the two groups. ${ }^{78}$ However, in naturalistic studies, adjunctive antidepressant use was associated with increased mania symptom severity and 
did not appear to reduce the time to recovery compared to treatment with mood stabilizer alone. ${ }^{79}$ Antidepressant use also exacerbated the clinical course of rapid cycling BD but was not associated with the development of suicidality. ${ }^{80}$

Regarding treatment-resistant bipolar depression, a randomized study was conducted to compare the effectiveness of lamotrigine, inositol, and risperidone. Although significant statistical differences were found in the primary analysis, lamotrigine was more effective in terms of CGI and functional levels in the post-hoc analysis. ${ }^{81}$ The study also explored the efficacy of psychosocial intervention for BD. Intensive psychosocial intervention, such as interpersonal and social rhythm therapy, cognitive behavior therapy, and family-focused therapy, enhanced functioning and life satisfaction in patients with $\mathrm{BD} .^{82}$

In a naturalistic study, patients with $\mathrm{BD}$ showed a high disease burden even during standard clinical care. Among the 1469 patients who were symptomatic at study entry, 858 (58\%) subsequently achieved remission during follow-up. ${ }^{83}$ Nearly $50 \%$ of these patients experienced recurrence during the 2 years of follow-up. Residual mood symptoms at initial recovery were associated with increased risk of recurrence. Although this is generally consistent with other reports, it suggests that the predominance of depressive relapse over manic relapse is substantially lower than was reported in the CDS study.

The study also confirmed the complex disease presentation of $\mathrm{BD}$. BD showed high rates of psychiatric and medical comorbid conditions, ${ }^{84}$ which were associated with poorer clinical courses. Mixed features were common, ${ }^{85}$ and anxiety comorbidity increased suicide risk ${ }^{86}$ and worsened clinical courses. ${ }^{87}$ Polypharmacy was also very common, ${ }^{88}$ and about $10 \%$ of patients were treated with the second-generation atypical antipsychotics. ${ }^{89}$ Similar to the STAR*D study, genetic studies are actively being done in combination with sophisticated phenotype definition using the database. ${ }^{90-94}$

\section{Limitations}

Also similar to the STAR*D study, participants in the STEP$\mathrm{BD}$ may not be representative of the general population with BD. In order to reflect the real-world clinical setting, patients who visited and sought treatment at the study sites were recruited. Thus, this study's population may be different from the population of the epidemiological study. Additionally, although the study team made an effort to recruit people within the minority population, Asian and Latino subjects were underrepresented.

\section{The Stanley Foundation Bipolar treatment outcome Network}

The NIMH SFBN ${ }^{95}$ is a multisite clinical trials network that has been established to determine the relative efficacy of treatments for BDs that can address a wide range of variants and comorbidities of disease, which are the main characteristics of BD. Subjects were recruited from four sites in the United States (Los Angeles, Dallas, Cincinnati, and Bethesda) and one site in Europe (Utrecht, Netherlands). All participants were community-based subjects diagnosed with either BD I, II or not otherwise specified (NOS). The network was designed to conduct multi-level randomized controlled clinical trials. More than 600 subjects were recruited, and 125 of these subjects participated in the randomized controlled clinical trials.

At baseline, all patients received the Structured Clinical Interview (SCID) for DSM-IV, Research Version (SCID-P). ${ }^{96}$ Socio-demographic and clinical information were collected through self-report questionnaires and an individual interview with a clinician.

The NIMH Life Chart Manual for recurrent affective illness (NIMH-LCM) $)^{97}$ was used for long-term assessment. In the LCM self-version of prospective ratings (LCM-S/P), ${ }^{98}$ each subject was instructed to record daily mood changes as well as functional levels and important life events. The clinician integrated information from the LCM-S/P and interview and finalized the NIMH Clinician version of the Prospective ratings (the NIMH-LCM-C/P). ${ }^{98}$ Moreover, additional information was collected through the 30-item Inventory for Depressive Symptomatology (IDS) ${ }^{99}$ for depression, the Young Mania Rating Scale (YMRS) for mania, the Positive and Negative Syndrome Scale (PANSS) ${ }^{100}$ for psychosis, the Global Assessment of Functional Scale (GAF) ${ }^{101}$ for social and occupational functioning, and the Life Functioning Questionnaire $(\mathrm{LFQ})^{102}$ for quality of life.

\section{Major findings}

The SFBN included three double blind, randomized, controlled studies on adjunctive agents for BD103: 1) adjunctive use of bupropion, sertraline and venlafaxine; 2) omega-3 versus placebo; and 3) modafinil versus placebo. Adjunctive use of antidepressants confirmed the risk of (hypo)manic switch in antidepressant use, which occurred less often in bipolar II disorder compared to bipolar I disorder. ${ }^{104}$ Among the three antidepressants examined, venlafaxine was associated with the highest risk of (hypo)manic switch. ${ }^{105}$ In the study on adjunctive use of omega-3, there was no significant difference in mood systems between the use of omega- 3 and the placebo, ${ }^{106}$ while modafinil trials showed significant improvement of depressive symptoms compared to the placebo trials. ${ }^{107}$ Also, two open randomized trials (tranylcypromine vs. lamotrigine; sibutramine vs. topiramate) were conducted; tranylcypromine showed promising efficacy in treating depres- 
sive symptoms compared to lamotrigine. ${ }^{108}$ Both sibutramine and topiramate, however, had significant side effects, such as weight loss. Topiramate had a higher discontinuation rate. In addition to randomized trials, numerous open-label, naturalistic case series on adjunctive use of anticonvulsants (gabapentin, zonisamide, levetiracetam, topiramate, lamotrigine, tiagabine and oxcarbazepine) $)^{109-112}$ and atypical antipsychotics (olanzapine, risperidone, quetiapine, clozapine and aripiprazole $)^{113,114}$ were reported.

The study also confirmed the chronic and recurrent nature of BD. A majority of subjects had a considerable degree of residual illness-related morbidity, with a three-fold greater amount of time spent depressed than manic. ${ }^{103}$ The study also found that there was a time delay of more than a decade between the onset of symptoms that met the full criteria of the mood disorder and the onset of first treatment. Early life adversities (i.e., physical or sexual abuse) and a positive family history of mood disorders were associated with the early onset of BD. ${ }^{115}$ Both medical and psychiatric comorbidity were very common among the subjects. ${ }^{116}$ The severity of mood disorders was associated with having experienced mood episodes more than 10 times, a family history of drug abuse, and poor occupational functioning. The study also found that gender affected disease presentation. ${ }^{117-119}$

\section{Limitations}

The study did not collect any biological samples to determine a biomarker for the clinical courses of BD. Thorough evaluation through academic or tertiary-referral centers may limit recruiting samples that can represent bipolar disorder in general. More importantly, subjects in the study had the illness for an average of 20 years, so study findings may not be generalizable to those in a relatively early phase of the illness. In particular, considering the fact that most illness variables were gathered through self-report questionnaire and interviews, reliability regarding the disease course may be lower than expected.

\section{The Clinical Research Center for Depression study}

The Clinical Research Center for Depression (CRESCEND) study is a 9-year observational collaborative prospective cohort study examining clinical outcomes in patients with depressive disorders in Korea. ${ }^{120}$ From January 2006 to August 2008, 1,183 participants were enrolled in the CRESCEND study from 18 hospitals throughout Korea. The CRESCEND study endorsed a wide inclusion criteria; participants were over 7 years old and met the criteria for either MDD, dysthymic disorder, or depressive disorder, not otherwise specified (NOS), as determined by the SCID. ${ }^{96}$

The CRESCEND study included two phases with a follow- up period of 9 years. In phase I, which lasted a year, each eligible participant visited the hospital and was assessed at 1, 2, $4,8,12,24$, and 52 weeks after baseline. During phase II, an extension of phase I, all participants were given an annual evaluation from year 1 (or the end of phase I) to year 9 .

A diagnostic evaluation, retrospective personal history of medical or psychiatric illnesses and treatment, and socio-epidemiologic clinical data were collected at baseline. Clinical, social, and functional outcomes of the treatment were evaluated with clinician- and self-administered measures during each visit. The clinician-administered measures included the $\mathrm{CGI}^{42}$ the $\mathrm{HRSD}_{17},{ }^{40}$ the Hamilton Anxiety Rating Scale (HAMA) ${ }^{121}$ the Brief Psychiatric Rating Scale (BPRS), ${ }^{122}$ and the Social and Occupational Functioning Assessment Scale (SOFAS). ${ }^{10}$ The self-administered measures consisted of the BDI-II, ${ }^{73}$ the Scale for Suicidal Ideation (SSI), ${ }^{123}$ and the abbreviated version of the World Health Organization Quality of Life assessment instrument (WHO-QOL-BREF). ${ }^{124}$

Major findings

The CRESCEND study is the first long-term prospective collaborative observational cohort study investigating the natural course and outcome for depressive patients in Korea. Baseline data from the study showed distinct characteristics of depression in Korea. Subjects with depression in Korea showed an older age of onset, more frequent histories of suicide attempts and lower rates of family history of depression than previous studies in the Western countries. ${ }^{125}$ These characteristics may be associated with biological and sociocultural characteristics of Korean MDD, with important implications for treatment plans and courses. The phase II follow-up assessments are currently in progress. The remission rate after 12 weeks of antidepressant treatment was $31.4 \%$; female subjects without a history of prior suicide attempt and with low baseline anxiety were found to have a higher remission rate. $^{126,127}$

\section{Limitations}

The study included all spectrums of depression; however, it did not include patients with BDs. About three-fourths of the participants in the CRESCEND study were recruited from outpatient settings, which may cause selection bias.

\section{CONCLUSION}

So far, various cohort studies on mood disorders provided crucial information on the complex course of mood disorders, building a foundation for clinical and biological research. However, there are several limitations in directly applying the study findings to real world clinical settings. In particular, 
most studies explored clinical courses of populations with depression and BD separately, even though there has been controversy over whether the two diseases are within the same spectrum or have distinct neurobiological backgrounds. Considering the heterogeneous illness presentation and the transition from unipolar depression to bipolar disorder, which is not uncommon, it would be preferable to apply loose criteria using standardized evaluation methods to include a broad range of patients with mood disorders. In order to understand the detailed clinical course, close observation is necessary, and follow-ups should occur more frequently. Previous clinical trials have generally gathered detailed information on the course, but there may have been a potential bias in their recruitment process. Regular naturalistic followup evaluations will give us the best opportunity to observe the clinical course more closely. Moreover, it is ideal to have both an objective mood rating and a functional level evaluation during the evaluation visits. In addition, it is important to observe the early stages of illnesses to determine factors associated with chronicity or recurrence. In order to apply clinical information from naturalistic observations to early detection and treatment, biological samples should be collected at the same time. Aside from the CRESCEND study, the majority of participants in cohort studies were Caucasian, so the biopsychosocial characteristics of Asian populations with mood disorders have not been thoroughly investigated. An innovative cohort study that can serve as a platform for translational research for treatment and prevention of mood disorders is critical in determining clinical, psychosocial, neurobiological, and genetic factors that are associated with longterm course and consequences of mood disorders in Korean patients.

\section{Acknowledgments}

This study was supported by the Korea Health 21 R\&D Project funded by the Ministry of Health \& Welfare, Republic of Korea (HM14C2606).

\section{REFERENCES}

1. Kessler RC, Aguilar-Gaxiola S, Alonso J, Chatterji S, Lee S, Ormel J, et al. The global burden of mental disorders: an update from the WHO World Mental Health (WMH) surveys. Epidemiol Psichiatr Soc 2009;18: 23-33.

2. Simon GE. Social and economic burden of mood disorders. Biol Psychiatry 2003;54:208-215.

3. Jeon HJ, Lee JY, Lee YM, Hong JP, Won SH, Cho SJ, et al. Lifetime prevalence and correlates of suicidal ideation, plan, and single and multiple attempts in a Korean nationwide study. J Nerv Ment Dis 2010; 198:643-646.

4. Jeon HJ, Lee JY, Lee YM, Hong JP, Won SH, Cho SJ, et al. Unplanned versus planned suicide attempters, precipitants, methods, and an association with mental disorders in a Korea-based community sample. J Affect Disord 2010;127:274-280.

5. Jeon HJ, Walker RS, Inamori A, Hong JP, Cho MJ, Baer L, et al. Differences in depressive symptoms between Korean and American outpa- tients with major depressive disorder. Int Clin Psychopharmacol 2014; 29:150-156.

6. Jeon HJ, Park JI, Fava M, Mischoulon D, Sohn JH, Seong S, et al. Feelings of worthlessness, traumatic experience, and their comorbidity in relation to lifetime suicide attempt in community adults with major depressive disorder. J Affect Disord 2014;166:206-212.

7. Munoz A, Gange SJ. Methodological issues for biomarkers and intermediate outcomes in cohort studies. Epidemiol Rev 1998;20:29-42.

8. Hagnell O, Ojesjo L. A prospective study concerning mental disorders of a total population investigated in 1947, 1957 and 1972. The Lundby study III (preliminary report). Acta Psychiatr Scand Suppl 1975;263:111.

9. The National Board of Health and Welfare. Patient Register. In: National Board of Health and Welfare, Editor. Stockholm: National Board of Health and Welfare; 2004.

10. American Psychiatric Association. Diagnostic and Statistical Manual of Mental Disorders. Washington, DC: American Psychiatric Association; 2000.

11. Mattisson C, Bogren M, Horstmann V, Munk-Jorgensen P, Nettelbladt P. The long-term course of depressive disorders in the Lundby Study. Psychol Med 2007;37:883-891.

12. Nettelbladt P, Bogren M, Mattisson C, Ojesjo L, Hagnell O, Hofvendahl E, et al. Does it make sense to do repeated surveys?--the Lundby Study, 1947-1997. Acta Psychiatr Scand 2005;111:444-452.

13. Angst J, Dobler-Mikola A, Binder J. The Zurich study--a prospective epidemiological study of depressive, neurotic and psychosomatic syndromes. I. Problem, methodology. Eur Arch Psychiatry Neurol Sci 1984; 234:13-20.

14. Derogatis LR, Cleary PA. Factorial invariance across gender for the primary symptom dimensions of the SCL-90. Br J Soc Clin Psychol 1977; 16:347-356.

15. Burns T, Eichenberger A, Eich D, Ajdacic-Gross V, Angst J, Rossler W. Which individuals with affective symptoms seek help? Results from the Zurich epidemiological study. Acta Psychiatr Scand 2003;108:419426.

16. Eich D, Neuhaus C, Gamma A, Angst J, Rossler W, Ajdacic-Gross V, et al. Is depression a risk factor for heart complaints? Longitudinal aspects in the Zurich study. Eur Arch Psychiatry Clin Neurosci 2007;257: 396-401.

17. Merikangas KR, Zhang H, Avenevoli S, Acharyya S, Neuenschwander $\mathrm{M}$, Angst J, et al. Longitudinal trajectories of depression and anxiety in a prospective community study: the Zurich Cohort Study. Arch Gen Psychiatry 2003;60:993-1000.

18. Angst J, Gamma A, Benazzi F, Ajdacic V, Rossler W. Does psychomotor agitation in major depressive episodes indicate bipolarity? Evidence from the Zurich Study. Eur Arch Psychiatry Clin Neurosci 2009;259: 55-63.

19. Merikangas KR, Herrell R, Swendsen J, Rossler W, Ajdacic-Gross V, Angst J. Specificity of bipolar spectrum conditions in the comorbidity of mood and substance use disorders: results from the Zurich cohort study. Arch Gen Psychiatry 2008;65:47-52.

20. Katz MM, Klerman GL. Introduction: overview of the clinical studies program. Am J Psychiatry 1979;136:49-51.

21. Endicott J, Spitzer RL. A diagnostic interview: the schedule for affective disorders and schizophrenia. Arch Gen Psychiatry 1978;35:837-844.

22. Manni E, Bortolami R, Pettorossi VE, Lucchi ML, Callegari E. Afferent fibers and sensory ganglion cells within the oculomotor nerve in some mammals and man. II. Electrophysiological investigations. Arch Ital Biol 1978;116:16-24.

23. Keller MB, Lavori PW, Friedman B, Nielsen E, Endicott J, McDonaldScott P, et al. The Longitudinal Interval Follow-up Evaluation. A comprehensive method for assessing outcome in prospective longitudinal studies. Arch Gen Psychiatry 1987;44:540-548.

24. Leon AC, Solomon DA, Mueller TI, Turvey CL, Endicott J, Keller MB. The Range of Impaired Functioning Tool (LIFE-RIFT): a brief mea- 
sure of functional impairment. Psychol Med 1999;29:869-878.

25. Judd LL, Schettler PJ, Solomon DA, Maser JD, Coryell W, Endicott J, et al. Psychosocial disability and work role function compared across the long-term course of bipolar I, bipolar II and unipolar major depressive disorders. J Affect Disord 2008;108:49-58.

26. Judd LL, Akiskal HS, Maser JD, Zeller PJ, Endicott J, Coryell W, et al. Major depressive disorder: a prospective study of residual subthreshold depressive symptoms as predictor of rapid relapse. J Affect Disord 1998;50:97-108.

27. Judd LL, Akiskal HS, Schettler PJ, Endicott J, Leon AC, Solomon DA, et al. Psychosocial disability in the course of bipolar I and II disorders: a prospective, comparative, longitudinal study. Arch Gen Psychiatry 2005;62:1322-1330.

28. Judd LL, Schettler PJ, Akiskal HS, Coryell W, Leon AC, Maser JD, et al. Residual symptom recovery from major affective episodes in bipolar disorders and rapid episode relapse/recurrence. Arch Gen Psychiatry 2008;65:386-394.

29. Coryell W, Solomon DA, Fiedorowicz JG, Endicott J, Schettler PJ, Judd LL. Anxiety and outcome in bipolar disorder. Am J Psychiatry 2009; 166:1238-1243.

30. Judd LL, Akiskal HS, Schettler PJ, Coryell W, Maser J, Rice JA, et al. The comparative clinical phenotype and long term longitudinal episode course of bipolar I and II: a clinical spectrum or distinct disorders? J Affect Disord 2003;73:19-32.

31. Judd LL, Akiskal HS, Schettler PJ, Endicott J, Maser J, Solomon DA, et al. The long-term natural history of the weekly symptomatic status of bipolar I disorder. Arch Gen Psychiatry 2002;59:530-537.

32. Judd LL, Akiskal HS, Schettler PJ, Coryell W, Endicott J, Maser JD, et al. A prospective investigation of the natural history of the long-term weekly symptomatic status of bipolar II disorder. Arch Gen Psychiatry 2003;60:261-269.

33. Judd LL. Major depressive disorder: longitudinal symptomatic structure, relapse and recovery. Acta Psychiatr Scand 2001;104:81-83.

34. Fava M, Rush AJ, Trivedi MH, Nierenberg AA, Thase ME, Sackeim $\mathrm{HA}$, et al. Background and rationale for the sequenced treatment alternatives to relieve depression $\left(\mathrm{STAR}^{*} \mathrm{D}\right)$ study. Psychiatr Clin North Am 2003;26:457-494, x.

35. Sachs GS, Thase ME, Otto MW, Bauer M, Miklowitz D, Wisniewski SR, et al. Rationale, design, and methods of the systematic treatment enhancement program for bipolar disorder (STEP-BD). Biol Psychiatry 2003;53:1028-1042.

36. Penninx BW, Beekman AT, Smit JH, Zitman FG, Nolen WA, Spinhoven P, et al. The Netherlands Study of Depression and Anxiety (NESDA): rationale, objectives and methods. Int J Methods Psychiatr Res 2008;17:121-140.

37. Kessler RC, Abelson J, Demler O, Escobar JI, Gibbon M, Guyer ME, et al. Clinical calibration of DSM-IV diagnoses in the World Mental Health (WMH) version of the World Health Organization (WHO) Composite International Diagnostic Interview (WMHCIDI). Int J Methods Psychiatr Res 2004;13:122-139.

38. Rush AJ, Fava M, Wisniewski SR, Lavori PW, Trivedi MH, Sackeim HA, et al. Sequenced treatment alternatives to relieve depression (STAR*D): rationale and design. Control Clin Trials 2004;25:119-142.

39. Zimmerman M, Mattia JI. The reliability and validity of a screening Questionnaire for 13 DSM-IV Axis I disorders (the Psychiatric Diagnostic Screening Questionnaire) in psychiatric outpatients. J Clin Psychiatry 1999;60:677-683.

40. Hamilton M. A rating scale for depression. J Neurol Neurosurg Psychiatry 1960;23:56-62.

41. Rush AJ, Trivedi MH, Ibrahim HM, Carmody TJ, Arnow B, Klein DN, et al. The 16-Item Quick Inventory of Depressive Symptomatology (QIDS), clinician rating (QIDS-C), and self-report (QIDS-SR): a psychometric evaluation in patients with chronic major depression. Biol Psychiatry 2003;54:573-583.

42. Busner J, Targum SD, Miller DS. The Clinical Global Impressions scale: errors in understanding and use. Compr Psychiatry 2009;50:257-262.

43. Alpert JE, Biggs MM, Davis L, Shores-Wilson K, Harlan WR, Schneider GW, et al. Enrolling research subjects from clinical practice: ethi$\mathrm{cal}$ and procedural issues in the Sequenced Treatment Alternatives to Relieve Depression (STAR*D) trial. Psychiatry Res 2006;141:193-200.

44. Rush AJ, Trivedi MH, Wisniewski SR, Nierenberg AA, Stewart JW, Warden $\mathrm{D}$, et al. Acute and longer-term outcomes in depressed outpatients requiring one or several treatment steps: a STAR*D report. Am J Psychiatry 2006;163:1905-1917.

45. Gaynes BN, Rush AJ, Trivedi M, Wisniewski SR, Balasubramani GK, Spencer DC, et al. A direct comparison of presenting characteristics of depressed outpatients from primary vs. specialty care settings: preliminary findings from the STAR*D clinical trial. Gen Hosp Psychiatry 2005;27:87-96.

46. Nierenberg AA, Fava M, Trivedi MH, Wisniewski SR, Thase ME, McGrath PJ, et al. A comparison of lithium and T(3) augmentation following two failed medication treatments for depression: a STAR*D report. Am J Psychiatry 2006;163:1519-1530; quiz 1665.

47. McGrath PJ, Stewart JW, Fava M, Trivedi MH, Wisniewski SR, Nierenberg AA, et al. Tranylcypromine versus venlafaxine plus mirtazapine following three failed antidepressant medication trials for depression: a STAR*D report. Am J Psychiatry 2006;163:1531-1541; quiz 1666.

48. Thase ME, Friedman ES, Biggs MM, Wisniewski SR, Trivedi MH, Luther JF, et al. Cognitive therapy versus medication in augmentation and switch strategies as second-step treatments: a STAR*D report. Am J Psychiatry 2007;164:739-752.

49. American Psychiatric Association. Diagnostic and Statistical Manual of Mental Disorders. Washington, DC: American Psychiatric Association; 2013.

50. Gilmer WS, Trivedi MH, Rush AJ, Wisniewski SR, Luther J, Howland $\mathrm{RH}$, et al. Factors associated with chronic depressive episodes: a preliminary report from the STAR-D project. Acta Psychiatr Scand 2005;112: 425-433.

51. Perlis RH, Uher R, Ostacher M, Goldberg JF, Trivedi MH, Rush AJ, et al. Association between bipolar spectrum features and treatment outcomes in outpatients with major depressive disorder. Arch Gen Psychiatry 2011;68:351-360.

52. Perlis RH, Fava M, Trivedi MH, Alpert J, Luther JF, Wisniewski SR, et al. Irritability is associated with anxiety and greater severity, but not bipolar spectrum features, in major depressive disorder. Acta Psychiatr Scand 2009;119:282-289.

53. Yates WR, Mitchell J, Rush AJ, Trivedi MH, Wisniewski SR, Warden $\mathrm{D}$, et al. Clinical features of depressed outpatients with and without co-occurring general medical conditions in STAR ${ }^{\star}$ D. Gen Hosp Psychiatry 2004;26:421-429.

54. Bryan CJ, Songer TJ, Brooks MM, Thase ME, Gaynes BN, Klinkman $\mathrm{M}$, et al. A comparison of baseline sociodemographic and clinical characteristics between major depressive disorder patients with and without diabetes: a STAR*D report. J Affect Disord 2008;108:113-120.

55. Kozel FA, Trivedi MH, Wisniewski SR, Miyahara S, Husain MM, Fava $\mathrm{M}$, et al. Treatment outcomes for older depressed patients with earlier versus late onset of first depressive episode: a Sequenced Treatment Alternatives to Relieve Depression (STAR*D) report. Am J Geriatr Psychiatry 2008;16:58-64.

56. Gilmer WS, Gollan JK, Wisniewski SR, Howland RH, Trivedi MH, Miyahara S, et al. Does the duration of index episode affect the treatment outcome of major depressive disorder? A STAR*D report. J Clin Psychiatry 2008;69:1246-1256.

57. Binder EB, Owens MJ, Liu W, Deveau TC, Rush AJ, Trivedi MH, et al. Association of polymorphisms in genes regulating the corticotropin-releasing factor system with antidepressant treatment response. Arch Gen Psychiatry 2010;67:369-379.

58. Laje G, Paddock S, Manji H, Rush AJ, Wilson AF, Charney D, et al. Genetic markers of suicidal ideation emerging during citalopram treatment of major depression. Am J Psychiatry 2007;164:1530-1538. 
59. Warden D, Rush AJ, Wisniewski SR, Lesser IM, Kornstein SG, Balasubramani GK, et al. What predicts attrition in second step medication treatments for depression?: a STAR*D Report. Int J Neuropsychopharmacol 2009;12:459-473.

60. Cabanero M, Laje G, Detera-Wadleigh S, McMahon FJ. Association study of phosphodiesterase genes in the Sequenced Treatment Alternatives to Relieve Depression sample. Pharmacogenet Genomics 2009; 19:235-238.

61. Paddock S, Laje G, Charney D, Rush AJ, Wilson AF, Sorant AJ, et al. Association of GRIK4 with outcome of antidepressant treatment in the STAR*D cohort. Am J Psychiatry 2007;164:1181-1188.

62. Perlis RH, Purcell S, Fava M, Fagerness J, Rush AJ, Trivedi MH, et al. Association between treatment-emergent suicidal ideation with citalopram and polymorphisms near cyclic adenosine monophosphate response element binding protein in the STAR*D study. Arch Gen Psychiatry 2007;64:689-697.

63. Perlis RH, Moorjani P, Fagerness J, Purcell S, Trivedi MH, Fava M, et al. Pharmacogenetic analysis of genes implicated in rodent models of antidepressant response: association of TREK1 and treatment resistance in the STAR $(*)$ D study. Neuropsychopharmacology 2008;33: 2810-2819.

64. Lekman M, Laje G, Charney D, Rush AJ, Wilson AF, Sorant AJ, et al. The FKBP5-gene in depression and treatment response--an association study in the Sequenced Treatment Alternatives to Relieve Depression (STAR*D) Cohort. Biol Psychiatry 2008;63:1103-1110.

65. Bowden CL, Perlis RH, Thase ME, Ketter TA, Ostacher MM, Calabrese JR, et al. Aims and results of the NIMH systematic treatment enhancement program for bipolar disorder (STEP-BD). CNS Neurosci Ther 2012;18:243-249.

66. Sheehan DV, Lecrubier Y, Sheehan KH, Amorim P, Janavs J, Weiller E, et al. The Mini-International Neuropsychiatric Interview (M.I.N.I.): the development and validation of a structured diagnostic psychiatric interview for DSM-IV and ICD-10. J Clin Psychiatry 1998;59(Suppl 20):22-33; quiz 34-57.

67. Sachs GS. Use of clonazepam for bipolar affective disorder. J Clin Psychiatry 1990;51(Suppl 31-34); discussion 50-53.

68. Williams JB, Kobak KA. Development and reliability of a structured interview guide for the Montgomery Asberg Depression Rating Scale (SIGMA). Br J Psychiatry 2008;192:52-58.

69. Young RC, Biggs JT, Ziegler VE, Meyer DA. A rating scale for mania: reliability, validity and sensitivity. Br J Psychiatry 1978;133:429-435.

70. Liebowitz MR. Social phobia. Mod Probl Pharmacopsychiatry 1987; 22:141-173.

71. Shear MK, Brown TA, Barlow DH, Money R, Sholomskas DE, Woods SW, et al. Multicenter collaborative panic disorder severity scale. Am J Psychiatry 1997;154:1571-1575.

72. Goodman WK, Price LH, Rasmussen SA, Mazure C, Fleischmann RL, Hill CL, et al. The Yale-Brown Obsessive Compulsive Scale. I. Development, use, and reliability. Arch Gen Psychiatry 1989;46:10061011.

73. Beck AT, Ward CH, Mendelson M, Mock J, Erbaugh J. An inventory for measuring depression. Arch Gen Psychiatry 1961;4:561-571.

74. McCrae RR, John OP. An introduction to the five-factor model and its applications. J Pers 1992;60:175-215.

75. Beck AT, Epstein N, Brown G, Steer RA. An inventory for measuring clinical anxiety: psychometric properties. J Consult Clin Psychol 1988; 56:893-897.

76. Ware JE Jr. Sherbourne CD. The MOS 36-item short-form health survey (SF-36). I. Conceptual framework and item selection. Med Care 1992;30:473-483.

77. Harel EV, Levkovitz Y. Effectiveness and safety of adjunctive antidepressants in the treatment of bipolar depression: a review. Isr J Psychiatry Relat Sci 2008;45:121-128.

78. Ghaemi SN, Ostacher MM, El-Mallakh RS, Borrelli D, Baldassano CF, Kelley ME, et al. Antidepressant discontinuation in bipolar depression: a
Systematic Treatment Enhancement Program for Bipolar Disorder (STEP-BD) randomized clinical trial of long-term effectiveness and safety. J Clin Psychiatry 2010;71:372-380.

79. Goldberg JF, Perlis RH, Ghaemi SN, Calabrese JR, Bowden CL, Wisniewski S, et al. Adjunctive antidepressant use and symptomatic recovery among bipolar depressed patients with concomitant manic symptoms: findings from the STEP-BD. Am J Psychiatry 2007;164:13481355 .

80. Bauer MS, Wisniewski SR, Marangell LB, Chessick CA, Allen MH, Dennehy EB, et al. Are antidepressants associated with new-onset suicidality in bipolar disorder? A prospective study of participants in the Systematic Treatment Enhancement Program for Bipolar Disorder (STEP-BD). J Clin Psychiatry 2006;67:48-55.

81. Nierenberg AA, Ostacher MJ, Calabrese JR, Ketter TA, Marangell LB, Miklowitz DJ, et al. Treatment-resistant bipolar depression: a STEP-BD equipoise randomized effectiveness trial of antidepressant augmentation with lamotrigine, inositol, or risperidone. Am J Psychiatry 2006; 163:210-216.

82. Miklowitz DJ, Otto MW, Frank E, Reilly-Harrington NA, Kogan JN, Sachs GS, et al. Intensive psychosocial intervention enhances functioning in patients with bipolar depression: results from a 9-month randomized controlled trial. Am J Psychiatry 2007;164:1340-1347.

83. Perlis RH, Ostacher MJ, Patel JK, Marangell LB, Zhang H, Wisniewski SR, et al. Predictors of recurrence in bipolar disorder: primary outcomes from the Systematic Treatment Enhancement Program for Bipolar Disorder (STEP-BD). Am J Psychiatry 2006;163:217-224.

84. Magalhaes PV, Kapczinski F, Nierenberg AA, Deckersbach T, Weisinger $\mathrm{D}$, Dodd $\mathrm{S}$, et al. Illness burden and medical comorbidity in the Systematic Treatment Enhancement Program for Bipolar Disorder. Acta Psychiatr Scand 2012;125:303-308.

85. Goldberg JF, Perlis RH, Bowden CL, Thase ME, Miklowitz DJ, Marangell LB, et al. Manic symptoms during depressive episodes in 1,380 patients with bipolar disorder: findings from the STEP-BD. Am J Psychiatry 2009;166:173-181.

86. Simon NM, Zalta AK, Otto MW, Ostacher MJ, Fischmann D, Chow $\mathrm{CW}$, et al. The association of comorbid anxiety disorders with suicide attempts and suicidal ideation in outpatients with bipolar disorder. J Psychiatr Res 2007;41:255-264.

87. Otto MW, Simon NM, Wisniewski SR, Miklowitz DJ, Kogan JN, Reilly-Harrington NA, et al. Prospective 12-month course of bipolar disorder in out-patients with and without comorbid anxiety disorders. Br J Psychiatry 2006;189:20-25.

88. Ghaemi SN, Hsu DJ, Thase ME, Wisniewski SR, Nierenberg AA, Miyahara S, et al. Pharmacological Treatment Patterns at Study Entry for the First 500 STEP-BD Participants. Psychiatr Serv 2006;57:660-665.

89. Brooks JO 3rd, Goldberg JF, Ketter TA, Miklowitz DJ, Calabrese JR, Bowden CL, et al. Safety and tolerability associated with second-generation antipsychotic polytherapy in bipolar disorder: findings from the Systematic Treatment Enhancement Program for Bipolar Disorder. J Clin Psychiatry 2011;72:240-247.

90. Huang J, Perlis RH, Lee PH, Rush AJ, Fava M, Sachs GS, et al. Crossdisorder genomewide analysis of schizophrenia, bipolar disorder, and depression. Am J Psychiatry 2010;167:1254-1263.

91. Mansour HA, Talkowski ME, Wood J, Pless L, Bamne M, Chowdari $\mathrm{KV}$, et al. Serotonin gene polymorphisms and bipolar I disorder: focus on the serotonin transporter. Ann Med 2005;37:590-602.

92. Drago A, Giegling I, Schafer M, Hartmann AM, Friedl M, Konte B, et al. AKAP13, CACNA1, GRIK4 and GRIA1 genetic variations may be associated with haloperidol efficacy during acute treatment. Eur Neuropsychopharmacol 2013;23:887-894.

93. Drago A, Crisafulli C, Serretti A. The genetics of antipsychotic induced tremors: a genome-wide pathway analysis on the STEP-BD SCP sample. Am J Med Genet B Neuropsychiatr Genet 2011;156B:975-986.

94. Howrigan DP, Laird NM, Smoller JW, Devlin B, McQueen MB. Using linkage information to weight a genome-wide association of bipolar 
disorder. Am J Med Genet B Neuropsychiatr Genet 2011;156B:462471.

95. Post RM, Nolen WA, Kupka RW, Denicoff KD, Leverich GS, Keck PE, Jr, et al. The Stanley Foundation Bipolar Network. I. Rationale and methods. Br J Psychiatry Suppl 2001;41:s169-s176.

96. First MB, Spitzer RL, Gibbon M, Williams JB. Structured Clinical Interview for DSM-IV-TR Axis I Disorders, Research Version, Patient Edition. (SCID-I/P) Biometrics Research. New York: New York State Psychiatric Institute, New York; 2002.

97. Denicoff KD, Leverich GS, Nolen WA, Rush AJ, McElroy SL, Keck PE, et al. Validation of the prospective NIMH-Life-Chart Method (NIMH-LCM-p) for longitudinal assessment of bipolar illness. Psychol Med 2000;30:1391-1397.

98. Born C, Amann BL, Grunze H, Post RM, Schärer L. Saving time and money: a validation of the self ratings on the prospective NIMH LifeChart Method (NIMH-LCM). BMC Psychiatry 2014;14:130.

99. Rush AJ, Giles DE, Schlesser MA, Fulton CL, Weissenburger J, Burns C. The Inventory for Depressive Symptomatology (IDS): preliminary findings. Psychiatry Res 1986;18:65-87.

100. Kay SR, Fiszbein A, Opler LA. The positive and negative syndrome scale (PANSS) for schizophrenia. Schizophr Bull 1987;13:261-276.

101. Krzyminska E, Rossa G, Krzyminski S. [The Global Deterioration Scale (GDS) and Functional Assessment Staging (FAST) in the diagnosis of Alzheimer type dementia]. Psychiatr Pol 1993;27:129-138.

102. Altshuler L, Mintz J, Leight K. The Life Functioning Questionnaire (LFQ): a brief, gender-neutral scale assessing functional outcome. Psychiatry Res 2002;112:161-182.

103. Post RM, Leverich GS, Altshuler LL, Frye MA, Suppes TM, Keck PE $\mathrm{Jr}$, et al. An overview of recent findings of the Stanley Foundation Bipolar Network (Part I). Bipolar Disord 2003;5:310-319.

104. Altshuler LL, Suppes T, Black DO, Nolen WA, Leverich G, Keck PE Jr, et al. Lower switch rate in depressed patients with bipolar II than bipolar I disorder treated adjunctively with second-generation antidepressants. Am J Psychiatry 2006;163:313-315.

105. Post RM, Altshuler LL, Frye MA, Suppes T, Rush AJ, Keck PE Jr, et al. Rate of switch in bipolar patients prospectively treated with secondgeneration antidepressants as augmentation to mood stabilizers. Bipolar Disord 2001;3:259-265.

106. Keck PE Jr, Mintz J, McElroy SL, Freeman MP, Suppes T, Frye MA, et al. Double-blind, randomized, placebo-controlled trials of ethyl-eicosapentanoate in the treatment of bipolar depression and rapid cycling bipolar disorder. Biol Psychiatry 2006;60:1020-1022.

107. Frye MA, Grunze H, Suppes T, McElroy SL, Keck PE Jr, Walden J, et al. A placebo-controlled evaluation of adjunctive modafinil in the treatment of bipolar depression. Am J Psychiatry 2007;164:1242-1249.

108. Nolen WA, Kupka RW, Hellemann G, Frye MA, Altshuler LL, Leverich GS, et al. Tranylcypromine vs. lamotrigine in the treatment of refractory bipolar depression: a failed but clinically useful study. Acta Psychiatr Scand 2007;115:360-365.

109. McElroy SL, Suppes T, Keck PE, Frye MA, Denicoff KD, Altshuler LL, et al. Open-label adjunctive topiramate in the treatment of bipolar disorders. Biol Psychiatry 2000;47:1025-1033.

110. Suppes T, Brown ES, McElroy SL, Keck PE Jr, Nolen W, Kupka R, et al. Lamotrigine for the treatment of bipolar disorder: a clinical case series. J Affect Disord 1999;53:95-98.

111. Suppes T, Chisholm KA, Dhavale D, Frye MA, Altshuler LL, McElroy
SL, et al. Tiagabine in treatment refractory bipolar disorder: a clinical case series. Bipolar Disord 2002;4:283-289.

112. Hummel B, Walden J, Stampfer R, Dittmann S, Amann B, Sterr A, et al. Acute antimanic efficacy and safety of oxcarbazepine in an open trial with an on-off-on design. Bipolar Disord 2002;4:412-417.

113. McElroy SL, Frye M, Denicoff K, Altshuler L, Nolen W, Kupka R, et al. Olanzapine in treatment-resistant bipolar disorder. J Affect Disord 1998;49:119-122.

114. Suppes T, McElroy SL, Keck PE, Altshuler L, Frye MA, Grunze H, et al. Use of quetiapine in bipolar disorder: a case series with prospective evaluation. Int Clin Psychopharmacol 2004;19:173-174.

115. Leverich GS, McElroy SL, Suppes T, Keck PE Jr, Denicoff KD, Nolen WA, et al. Early physical and sexual abuse associated with an adverse course of bipolar illness. Biol Psychiatry 2002;51:288-297.

116. McElroy SL, Altshuler LL, Suppes T, Keck PE Jr, Frye MA, Denicoff $\mathrm{KD}$, et al. Axis I psychiatric comorbidity and its relationship to historical illness variables in 288 patients with bipolar disorder. Am J Psychiatry 2001;158:420-426.

117. Frye MA, Altshuler LL, McElroy SL, Suppes T, Keck PE, Denicoff K, et al. Gender differences in prevalence, risk, and clinical correlates of alcoholism comorbidity in bipolar disorder. Am J Psychiatry 2003;160: 883-889.

118. Altshuler LL, Kupka RW, Hellemann G, Frye MA, Sugar CA, McElroy SL, et al. Gender and depressive symptoms in 711 patients with bipolar disorder evaluated prospectively in the Stanley Foundation bipolar treatment outcome network. Am J Psychiatry 2010;167:708-715.

119. Shivakumar G, Bernstein IH, Suppes T, Stanley Foundation Bipolar Network, Keck PE, McElroy SL, et al. Are bipolar mood symptoms affected by the phase of the menstrual cycle? J Womens Health (Larchmt) 2008;17:473-478.

120. Park MH, Kim TS, Yim HW, Jeong SH, Lee C, Lee CU, et al. Clinical characteristics of depressed patients with a history of suicide attempts: results from the CRESCEND study in South Korea. J Nerv Ment Dis 2010;198:748-754.

121. Hamilton M. The assessment of anxiety states by rating. Br J Med Psychol 1959;32:50-55.

122. Overall J, Gorham D. The Brief Psychiatric Rating Scale. Psychol Rep 1962;10:779-812.

123. Beck AT, Kovacs M, Weissman A. Assessment of suicidal intention: the Scale for Suicide Ideation. J Consult Clin Psychol 1979;47:343-352.

124. Development of the World Health Organization WHOQOL-BREF quality of life assessment. The WHOQOL Group. Psychol Med 1998;28: 551-558.

125. Kim TS, Jeong SH, Kim JB, Lee MS, Kim JM, Yim HW, et al. The clinical research center for depression study: baseline characteristics of a korean long-term hospital-based observational collaborative prospective cohort study. Psychiatry Investig 2011;8:1-8.

126. Kim JM, Kim SW, Stewart R, Kim SY, Yoon JS, Jung SW, et al. Predictors of 12-week remission in a nationwide cohort of people with depressive disorders: the CRESCEND study. Hum Psychopharmacol 2011; 26:41-50.

127. Yang SJ, Kim SY, Stewart R, Kim JM, Shin IS, Jung SW, et al. Gender differences in 12-week antidepressant treatment outcomes for a naturalistic secondary care cohort: the CRESCEND study. Psychiatry Res 2011;189:82-90. 